A linguagem autônoma da luz como arte performativa: a alteração perceptiva através da luz e seu conteúdo narrativo

The autonomous language of light as performing art: perceptual alterations through light and its narratives

\title{
Mirella Brandi
}

Mirella Brandi

Mirella Brandi é designer de luz, artista multimídia e diretora artística formada em artes visuais pela Faculdade de Belas Artes, artes cênicas pela USJT e designer de luz pela CityLit London. É sócia-fundadora do Coletivo Phila7

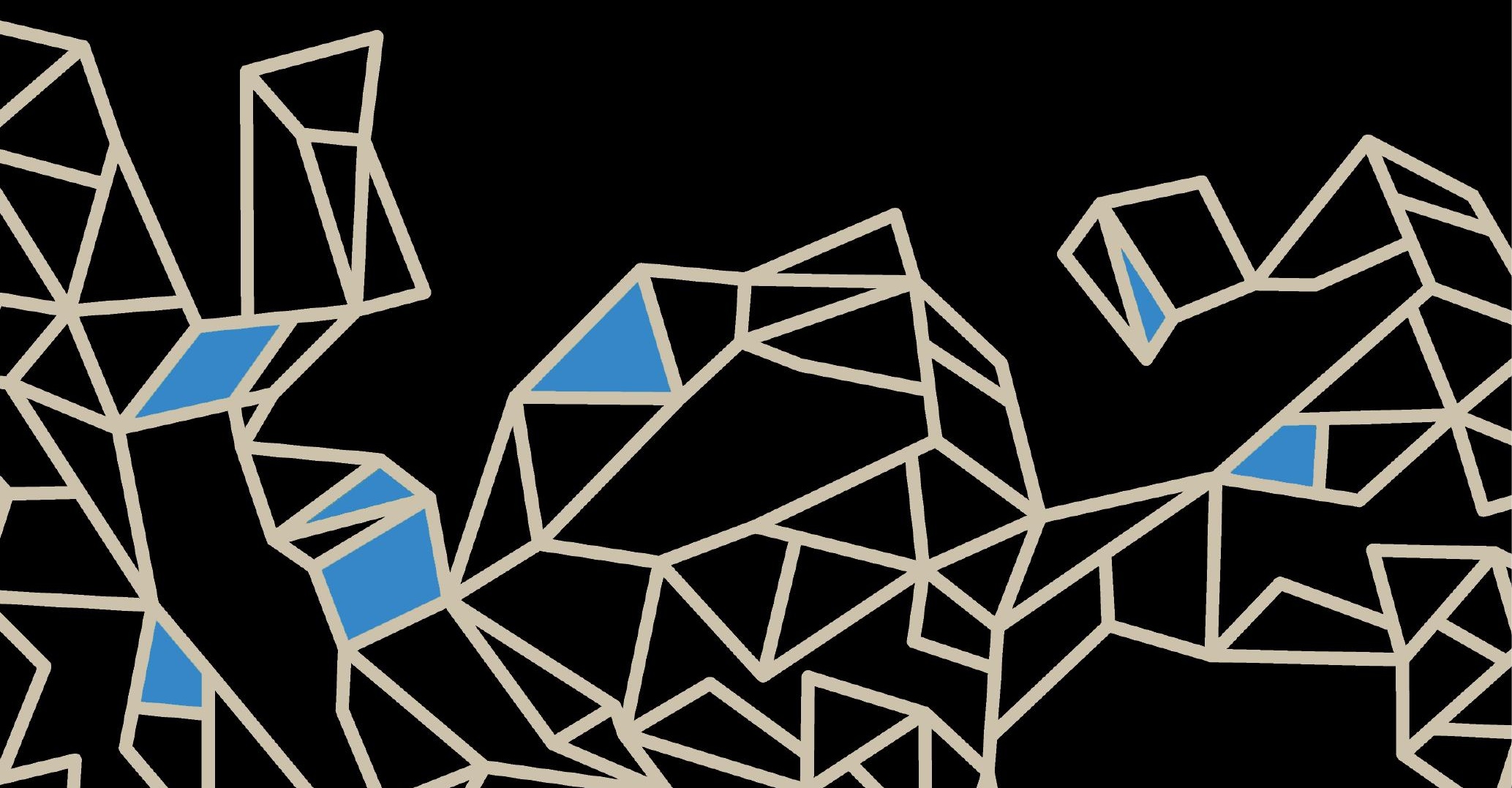




\section{Resumo}

Este artigo aborda a luz como linguagem autônoma de uma arte expandida que se apropria de inúmeros conceitos e técnicas de diversas áreas cênicas e visuais para a criação de narrativas subjetivas. Explora o lado perceptivo da luz como ferramenta artística que se estabelece por meio das artes visuais, do cinema expandido e da arte performativa. O texto evidencia conceitos de diferentes ordens, reunidos de modo singular através da luz. Inicia seu percurso citando algumas descobertas e teorias importantes sobre a natureza incerta da luz, e avança abordando a fusão de linguagens e pensamentos na arte. Um olhar é lançado para o que pode ser aprofundado e reorganizado na criação artística em diferentes áreas. O método investigativo transdisciplinar busca contribuir para a discussão deste tema ainda recente na esfera da iluminação como expressão artística.

Palavras-chave: Luz, Artes visuais, Arte performativa, Narrativa, Percepção.

\section{Abstract}

This article approaches light as an autonomous language within an expanded art form that appropriates many concepts and techniques from both performing and visual practices, in order to create subjective narratives. It addresses the exploration of the perceptual side of light as an artistic tool established in visual arts, expanded cinema and performing arts. The text highlights a wide range of concepts singularly gathered through light. It starts its journey by citing some important discoveries and theories about the uncertain nature of light, and moves forward through the fusion of languages and approaches on art. A glimpse is launched to what can be deepened and reorganized in artistic creation in different areas. The interdisciplinary investigative method seeks to contribute to the discussions around this recent subject in the sphere of lighting as artistic expression.

Keywords: Light, Visual art, Performing arts, Narratives, Perception. 


\section{Um breve olhar sobre a luz e a arte: a arte como espaço ampliado}

Meu trajeto na iluminação começou na área cênica, e embaralhou técnicas e conceitos que apontaram o início de um caminho artístico autônomo para a luz, que se estabeleceu através dos conceitos que definem as artes visuais e o audiovisual. Esse caminho autônomo consiste no potencial perceptivo da luz para a condução narrativa subjetiva dissociada do texto, da atuação, da coreografia ou de qualquer outro elemento. É o princípio que utilizo na criação de instalações imersivas nas artes visuais, de performances audiovisuais ao vivo e de espetáculos performativos, linguagens artísticas distintas abordadas nesse texto para se concluírem por meio de um olhar unificado que não delimita fronteiras, mas percebe a arte como espaço amplificado.

Por mais que relute, nesse momento não vejo mais sentido em definir as características de cada área dentro da arte, assim como não é possível definir a própria vida sem a interferência dos mais diversos acontecimentos que a preenchem e a transformam constantemente. A arte e a vida, no melhor de sua complexidade, estão envolvidas diretamente nesse diálogo subjetivo feito por meio da luz que atinge um espaço desconhecido e sem respostas definitivas.

A arte é vista aqui como campo neutro que permite o risco, a zona do desconforto, do desconhecido, para recriar um "não lugar" dentro de um lugar reconhecido, onde a tradição e os experimentos de risco podem e devem coabitar e coexistir. O palco como espaço de transgressão. A luz que impulsionava a trama agora é a própria trama. $O$ espectador é seu protagonista.

Esses elementos formam a matéria-prima para o desenvolvimento das narrativas de imersão perceptiva. Cada olhar ao nosso redor nos torna conscientes não só dos objetos vistos, mas das luzes que os iluminam. Cada diferente ângulo, cor e temperatura dessa luz pode alterar definitivamente o elemento observado, seja numa cena cotidiana ou trabalhada de forma cênica, visual ou cinematográfica. Sem luz, a visão é impotente. Quando transformamos a fonte de luz e o modo como a utilizamos, alteramos o comportamento do que vemos, e, consequentemente, nossa percepção de mundo se modifica.

É possível analisar a luz a partir do ponto de vista científico, filosófico e contemplativo para entender sua natureza. A ótica clássica, a teoria 
eletromagnética, as bases experimentais da física e a mecânica quântica da luz são caminhos preciosos para entender e estudar a luz sob o aspecto físico. Mas atingir o pleno entendimento do que é a luz parece não estar a nosso alcance. Em 1951, Albert Einstein afirmou que suas cinco décadas de estudos sobre luz não o fizeram chegar nem perto de um real entendimento dela. Foi ele que, em 1905, inspirado pela física quântica, embaralhou todas as convicções a respeito da luz, quando comprovou que ela se comporta ora como onda, ora como partícula. Essa comprovação Ihe daria o Prêmio Nobel e estabeleceria um novo espectro de afirmações sobre esse campo.

Em outro lado desse espectro de investigações, o escritor, pensador e poeta Johann Wolfgang von Goethe (1749-1832) passa mais de vinte anos tentando concluir o que considerava sua obra máxima: um tratado sobre as cores que colocaria abaixo a teoria de Newton, com sua afirmação de que a luz era feita de partículas indivisíveis. A principal objeção de Goethe a Newton era de que a luz branca não podia ser constituída por cores. Defendia a ideia das cores serem resultado da interação da luz com a "não luz", ou a escuridão. Mas talvez o principal aspecto das formulações de Goethe seja sua afirmação de que a luz não pode ser entendida com um fenômeno físico, pois um mesmo comprimento de onda pode ser percebido diferentemente por diferentes seres vivos. Ou seja, cor e luz são fenômenos de caráter subjetivo e individual. Se a física parte do estudo da observação do visível, nosso conhecimento depende diretamente de quem somos e de como pensamos. Uma cultura diferente, com outros métodos e percepções, chegaria a diferentes conclusões.

\section{A luz nas artes visuais}

Apesar de ter trabalhado durante muitos anos com iluminação cênica, as artes visuais estiveram sempre presentes em meu percurso e me levaram a reinterpretar certos conceitos, fazendo migrar técnicas específicas de uma área para outra, de forma a explorar o modo como essas técnicas alteram suas características, seu comportamento e sua finalidade quando utilizadas em contextos diferentes dos convencionais e como isso altera o modo de olharmos a luz e o que ela nos transmite. 
Reuni tais elementos para a pesquisa de um vocabulário que compreende a luz como linguagem artística autônoma, e o resultado pode se estabelecer tanto na área visual quanto na área cênica - já não importa. $O$ que interessa destacar é que alguns artistas e movimentos estéticos estão fortemente relacionados com a linguagem da luz, mesmo quando não a utilizam como objeto central da obra.

A op art (optical art), por exemplo, inspirada pelo desejo do movimento, utilizou a ilusão ótica para atingir seus resultados. O que fascina nela é o rígido e preciso caminho matemático para alcançar um movimento absolutamente mágico e enigmático, que salta aos olhos, e em que qualquer explicação lógica parece irrelevante diante da potência de tal percepção. Apesar do rigor com que é construída, a op art simboliza um mundo mutável e instável. Jesús Soto, forte referência dentro da op art, levou esse desejo de movimento ilusório até as últimas consequências.

Como desdobramento da op art, podemos observar notáveis experiências através da arte cinética, que explora os movimentos físicos mecanizados. Julio Le Parc é exemplo importante na apropriação da luz para a criação de obras cinéticas, assim como Abraham Palatnik, um dos pioneiros da arte cinética no Brasil.

Meu primeiro projeto artístico autoral, OP1, baseou-se nas técnicas utilizadas pela op art. Quatro artistas distintos, luz, imagem, corpo e música se fundiam num turbilhão ótico de interdependência. Tal fusão evidenciou o potencial narrativo desse cruzamento e marcou o início de um longo percurso de pesquisas sobre a subjetividade como forma de condução narrativa. Surge, nesse momento, uma longa e duradoura parceria com Muepetmo, músico que me acompanha na pesquisa e no desenvolvimento de projetos sobre narrativas imersivas construídas por meio da luz e do som.

As instalações imersivas nas artes visuais sugerem uma ruptura na contemplação por parte do espectador e apostam na imersão dos sentidos como forma de comunicação. Artistas como a coreana Kimsooja e o norte-americano James Turrell trabalham o espaço imersivo de forma magnífica, dentro de uma travessia fascinante que transporta o espectador para outra percepção, sem abrir concessões. Por meio desses trabalhos, compreende-se que a re- 
alidade dos fatos já é a própria teoria, como dizia Goethe. A ação ao invés da cena. O estar ao invés do contemplar. O ser ao invés do interpretar.

\section{A visual music}

Muito se fez nesse período para incorporar, mesclar e transferir conceitos e técnicas de diferentes formatos artísticos. Teorias e técnicas musicais foram adotadas para compreender e alterar a área visual, e vice-versa. O conceito de visual music é um dos resultados dessa prática, e marca a pesquisa sobre a musicalização nas artes visuais de um modo mais amplo. Nesse caso, a percepção da imagem e da luz é expandida por meio da música, com a luz e o som sendo compreendidos através de uma mesma onda. "Não mais conteúdo para simplesmente reproduzir o mundo visível, os pintores deveriam, ao invés disso, buscar preencher suas telas com intensidade emocional, integridade estrutural e pureza estética, como acontecia com a música” (ZILCZER, 2005, p. 24).

Dentro do escopo da visual art, a utilização da luz, por seu caráter imaterial, teve importância marcante na condução dos experimentos. Segundo as palavras do artista, arquiteto e poeta da visual music Theo van Doesburg, "se até agora alguém considerava a superfície de projeção uma tela emoldurada, é necessário eventualmente descobrir o espaço-luz, o filme continuum" (VAN DOESBURG, 1966, p. 9). ${ }^{1}$

O músico Thomas Wilfred foi um dos primeiros a explorar a luz em seu caráter imersivo, construindo, com a ajuda do seu estreito colaborador Claude Bragdon, vários modelos de Clavilux para induzir as luzes pelo espaço: "o uso mais elevado e a função suprema de uma arte da luz seriam tornar-se o acelerador da evolução humana e da expansão da consciência" (BRAGDON, 1918, p. 116).

\section{A luz e o audiovisual}

A inter-relação entre luz, imagem projetada e música é extremamente rica no que diz respeito à expansão das fronteiras entre áreas artísticas. São

1. A visual art teve um marco importante na criação do edifício projetado por Le Corbusier e lannis Xenakis por ocasião da Feira Mundial de Bruxelas, em 1958, chamado Pavilhão Philips. Foi a primeira grande obra multimídia, que se considera a primeira obra eletroacústica. 
vários os experimentos que agregam múltiplas linguagens e "explodem" a relação com o suporte, o espaço-tempo, as narrativas lineares e as imagens figurativas. O século XX, mais especificamente os anos 1970, com a entrada da tecnologia digital, marca o início de um período abundante para a relação da luz e da imagem na arte. Podemos encontrar inúmeras referências de fundamental importância, não apenas aquelas que apontam um caminho para a comunicação autônoma através da luz, mas especialmente as que dizem respeito à fusão entre linguagens artísticas distintas.

Inúmeros fatores e pesquisas anteriores a esse período também concorreram para o estabelecimento de tais experimentos, como a obra de Richard Wagner (1813-1883) maestro, compositor, diretor de teatro e ensaísta alemão que publica, em 1849, The artwork of the future, onde explora a experiência perceptiva do espectador na relação com o evento dramático e percebe a necessidade de aproximar todas as artes em uma síntese total de elementos: cenografia, imagem, música e texto. Wagner pretendia implementar com a "obra de arte total" um teatro que tivesse um efeito imersivo para o espectador diante de um espaço cênico transformado.

\section{O cinema}

Antes de ser visto como arte autônoma, o cinema se apropriava de múltiplas linguagens e invenções mecânicas para exibir trechos simples de um filme que despertava emoções vivas no público, e era chamado de "cinema das atrações." Tratava-se de algo diretamente relacionado ao que vemos hoje nos experimentos de live cinema, que aponta para a exploração múltipla entre linguagens na realização audiovisual ao vivo.

Em relação ao chamado "cinema expandido", é um termo bastante flexível que indica a expansão da linguagem cinematográfica para além de seus próprios códigos. A distorção e o deslocamento das convenções cinematográficas de espaço e tempo tinham como principal objetivo a expansão da consciência, mas também a experimentação em termos imagéticos e sonoros. O movimento tem sua origem no manifesto performático de Carlolee Schneemann e na publicação do livro Expanded cinema, de Gene Youngblood, que divide sua publicação em três aspectos: o primeiro funde 
todas as formas de arte, incluindo o filme, em um evento multimídia e de uma ação ao vivo; o segundo explora tecnologias eletrônicas e a chegada do ciberespaço, como enunciado por Marshall Mc Luha; o terceiro coloca por terra a barreira existente entre artista e público.

Muito artistas fizeram parte do movimento de cinema expandido e da videoarte, formando um belo time que revolucionou o audiovisual e os experimentos com imagem, som e performance. Entre eles, cito Nam June Paik, Andy Warhol, Peter Greenaway, John Cage e Anthony McCall, que utilizou a luz do projetor para enfatizar a qualidade escultural de um foco de luz. Mais recentemente, artistas como Ryoji Ikeda, AntiVJ, Nonotak e Robert Henke se apropriam dessas características para a criação multimídia, utilizando a luz em suas criações, como podemos ver em N_Polytope: behaviors in light and sound after lannis Xenakis, de Chris Salter, apreciador das ideias de Richard Wagner, que busca ambientes sensibilizados que utilizam a fusão do material arquitetônico com o som, a imagem e a luz.

No que se refere ao video mapping, surge como técnica que reconstrói o espaço real através da adição de um espaço virtual. Apesar de considerar a exploração dessa linguagem ainda bastante amparada pelo fascínio técnico, acredito que alguns artistas, como Can Buyukberber e Urbanscreen, extraem possibilidades brilhantes da espacialidade e da alteração de nossa percepção.

Percebo que os experimentos com audiovisual formam um rico alicerce de pesquisa para a linguagem da luz, pois agregam a base primordial do cinema, composta de luz e som. Explorar performances que utilizam apenas luz e som na condução ao vivo contribuiu, de forma potente, para realizar a síntese de uma narrativa subjetiva. Observar o resultado de tais experimentos alterou meu olhar a respeito da apropriação multidisciplinar na criação artística.

\section{Performatividade}

"What I love so much in this genre of non-dramatic literature is that you can attend somebody's thinking. I try to make it visible or audible." (GOEBBELS, 2015, site do artista) 
O teatro contemporâneo pode ser redefinido por meio dos conceitos de teatro performativo e de teatro pós-dramático, termo definido após a publicação do livro Postdramatisches theater, de Hans-Thies Lehmann, publicado na Alemanha em 1999, que defende um teatro visto para além do drama. Apenas na segunda metade do século XX, autores, principalmente os do teatro do absurdo, começam a construir uma dramaturgia fragmentária atravessada pelas artes da imagem, do cinema, das artes plásticas e do circo, impulsionadas pelo desenvolvimento das tecnologias na cena. "Na esteira [...] da onipresença das mídias na vida cotidiana desde os anos 1970 surge uma prática do discurso teatral nova e diversificada" (LEHMANN, 1999, p. 28). Esse olhar renovado, como compreende Lehmann, possibilita uma redefinição do status do diretor e do dramaturgo, não exigindo uma dependência recíproca ou centralizadora, elevando e igualando a importância de outras linguagens na construção da trama.

Josette Férral, crítica, teórica e professora, aproxima os conceitos da performance e da performatividade e os carrega para o que denomina teatro performativo. Segundo ela, o teatro se beneficiou das aquisições da performance, que transformam o ator em performer, o intérprete em persona e o texto em ação. Esses elementos caracterizam o teatro performativo. O estar no lugar do ser.

Alguns exemplos expressivos do teatro performativo são Heiner Goebbels, maestro, compositor e encenador que desestabiliza a hierarquia e o uso das linguagens artísticas no teatro, e Robert Lepage, que aposta na criação de uma poética tecnológica. Segundo Lepage, o teatro deve dar conta da evolução dos modos de narração, dos modos de percepção e compreensão do mundo. Outros exemplos podem ser citados, como o The Wooster Group, Ivo van Hove, o Teatro da Vertigem, o Coletivo Phila7 (que fundei com mais cinco artistas em 2004 e do qual participei durante dez anos), Laurie Anderson e, por fim, Chris Salter, que, mesmo sendo de outra área, produz obras que o aproximam do conceito de teatro performativo, como pode ser observado na performance IInix (2014).

Os conceitos de teatro pós-dramático e teatro performativo têm muitos aspectos em comum, especialmente no que diz respeito ao questionamento do poder centralizador do texto e à elevação de outras linguagens artísticas 
ao plano do texto, assumindo sua importância na construção da trama e da criação colaborativa. A relação do espectador com a trama, a permeabilidade das disciplinas e a multidisciplinaridade em cena são destacadas em ambos os casos. O que é realmente incompreensível, no entanto, é o fato de a iluminação não ter sido citada como exemplo de linguagem na definição de qualquer desses conceitos de teatro contemporâneo. A luz como possibilidade autônoma de criação e ação narrativa, totalmente permeável ao conceito de teatro performativo, ainda não foi cogitada.

Se pensarmos a luz como possibilidade narrativa subjetiva, que conduz uma ação performática para se redefinir através da percepção do espectador, estamos falando de questões de imaginação e relação desse espectador com a cena. Se a linguagem autônoma da luz para a criação performativa ainda não foi observada por críticos, diretores, teóricos e pensadores de teatro, acredito que já é tempo de sê-lo.

A pesquisa sobre narrativas subjetivas com luz - seja para a criação com múltiplas linguagens, seja por meio de performances que utilizam apenas luz e som em sua condução - não apenas se apropria de vários conceitos e técnicas do teatro, das artes visuais e do audiovisual, como também se define perfeitamente dentro de seu contexto: depois de um longo percurso que a distanciou das bases que definem o que é teatro, a luz, como caminho autônomo de linguagem, se encontra ressignificada por meio do conceito de teatro performativo.

\section{Mirella Brandi x Muepetmo}

Sob essa assinatura, existem nove anos de uma parceria que aprofunda a pesquisa da luz como linguagem autônoma na condução artística e hibridiza som e imagem no diálogo com múltiplas linguagens. A parceria se desdobra em inúmeros projetos de experimentação de linguagem, que se dividem em três eixos principais:

a) performances de imersão narrativa com luz e som;

b) instalações imersivas;

c) ações (espetáculos) sobre narrativas subjetivas com múltiplas linguagens. 
Desenvolver narrativas subjetivas através da luz me ajudou a enxergar no som e no silêncio as mesmas características, de forma complementar. Assim como as frequências de áudio não são percebidas pelo ouvido humano em sua totalidade, os comprimentos de ondas visíveis se encontram aproximadamente entre 380 e 750 frequências. Ondas mais curtas abrigam o ultravioleta, os raios $X$ e os raios gama. Ondas mais longas contêm o infravermelho, o calor, as micro-ondas e as ondas de rádio e televisão. O aumento de intensidade pode tornar perceptíveis ondas até então invisíveis, tornando os limites do espectro visível algo elástico, que a lógica científica nem sempre alcança. A música que o ouvido não capta pode ser sentida em diversas partes do corpo, e o silêncio em que acreditamos não existe de fato. O escuro cria imagens, assim como o silêncio possui sua própria música.

Explorar a comunicação subjetiva da luz e do som me levou a entender a criação artística com múltiplas linguagens por meio de outro ponto de vista. Não se trata de uma linguagem cênica e/ou visual que sugere seu ponto de partida através da luz e do som. Trata-se da exploração de uma linguagem que tem seus alicerces na condução narrativa subjetiva, que se define no espectador. É um conceito que desloca a própria relação entre público e artista e as convenções estabelecidas dentro de um teatro e de um espaço expositivo.

Trata-se de uma pesquisa que se apropria dos conceitos citados neste artigo, entre tantos outros, para agregar os múltiplos conteúdos e as inúmeras incertezas inerentes ao homem contemporâneo, pós-era digital, em que a palavra, somente, não parece suficiente para exprimir tal complexidade. Os mais diferentes olhares e conceitos se contaminam nesse pensamento e geram possibilidades infinitas de diálogo. A dramaturgia, que sempre teve seu alicerce construído por meio da palavra, cede espaço para a busca de caminhos menos conhecidos. Surge uma nova possibilidade dramatúrgica, que se define no espectador, por meio de sua percepção. A autonomia da luz atua como estímulo perceptivo para essa nova linguagem, e a criação artística como metáfora de uma nova percepção de mundo. A luz como polifonia aberta a novas percepções e olhares, assim como a arte e a vida. 
Reuni, neste artigo, parte importante de minha trajetória de pesquisa para chegar ao que compreendo hoje como luz - a luz como possibilidade de uma arte ampliada. O que me parece é que o fio tênue que delimita as linguagens artísticas e seus meios talvez nem exista mais, ou talvez não faça mais sentido em nossos tempos. Ou, se ainda existe, estamos em tempo de reavaliar essas diferenças e nos lançarmos em um pensamento mais unificado, o pensamento de uma arte ampla e colaborativa que acompanhe a evolução de nosso tempo. A arte entendida como pensamento transgressor, que compreende em si todo um universo de possibilidades direcionadas para a criação de olhares renovados.

\section{Referências bibliográficas}

BALL, S.; CURTIS, D. Expanded cinema: art, performance, film. Londres: Tate, 2011. BASTOS, M. Limiares das redes: escritos sobre arte e cultura contemporânea. São

Paulo: Intermeios; Fapesp, 2014.

BRAGDON, C. F. Harnessing the rainbow. In: Archicture and democracy. Nova York: A. A. Knopf, 1918.

COLLECTION Casa Daros. Julio le Parc kinetic works. Rio de Janeiro, 2004. FÉRAL, J. Por uma poética da performatividade: o teatro performativo. Sala Preta, São Paulo, v. 8, p. 197-210, 2008.

Além dos limites. São Paulo: Perspectiva, 2015.

FUSCO, R. de. Storia dell'arte contemporanea. Roma-Bari: Laterza,1983.

GOETHE, J.W. Doutrina das cores. São Paulo: Nova Alexandria, 2011.

GOUMARRE, L.; KIHM, C. Performance contemporaine. Paris: Airpress, 2008.

INSTITUTO TOMIE OTAKE. Soto: a construção da imaterialidade. Exposição. São Paulo, 2005.

LEHMANN, H. Le Théâtre post-dramatique. Paris: L'Arche, 2002.

NAUMANN, S. A Imagem Expandida sobre a musicalização das artes visuais no século vinte. TECCOGS, v. 6, p. 155-187, 2012.

NEWTON, I. Óptica. Trad. André Koch Assis. São Paulo: Edusp, 2002.

PAROLA, R. Optical art: theory and practice. Nova York: Dove, 1996.

SHYER, L. Robert Wilson and his collaborators. Londres: The Theatre Comunications Group, 1989.

SILVA, M. História da mecânica quântica 3: a natureza probabilística do mundo quântico e o princípio de incerteza. Artigonal, 1 fev. 2010.

SOLOMON R. GUGGENHEIM FOUNDATION. James Turrell. Exposição. Nova York: 2013. 
VAN DOESBURG, T. Film as pure form. Form, 1966.

WAGNER, R. The art-work of the future, and other works. Londres: W. Ashton Ellis, 1993.

YOUNGBLOOD, G. Expanded cinema. Nova York: E. P. Dutton, 1970.

ZILCZER, J. Music for the eyes: abstract painting and light art. Nova York: Thames \& Hudson, 2005.

Recebido em 23/08/2015

Aprovado em 02/09/2015

Publicado em 21/12/2015 